\title{
A view of European challenges in dental education
}

- Understand the influence of Europe on dental education.

- Appreciate the impact of Europe on dentistry education in the UK.

\author{
R. S. Hobson ${ }^{1}$
}

Since the Bologna declaration in 1999 there have been significant developments in undergraduate dental education.

The GDC and the UK dental education community need to rise to these challenges.

Since the Bologna Declaration (1999), Europe has been leading the harmonisation of education standards worldwide. The Bologna Declaration is an EU education ministerial agreement, the aim is to harmonise the EU higher education community in order to place the EU as a world leader in higher education and be able to compete in the global market for students. In dentistry it affects the national regulatory authorities (in the UK, the General Dental Council), the Association of European Universities and the Council of European Dentists. In dental education the aim is to harmonise the activity of the dental schools and to achieve the EU standards for a graduate to be registered within the European Union as a dentist.

It should be noted that the dental schools have a two way flow of information between themselves and their regulatory authorities, the universities and the dental societies but there is no obvious flow of information between the dental schools and the central EU system. However, over the past ten years the Association for Dental Education in Europe (ADEE) has become the leader and co-ordinator for dental education across Europe.

${ }^{1}$ Child Dental Health, Newcastle University School of Dental Sciences, Framlington Place, Newcastle upon Tyne, NE2 4BW

Correspondence to: Dr Ross Hobson

Email:r.s.hobson@ncl.ac.uk

\section{Refereed Paper}

Accepted 22 October 2008

DOI: 10.1038/sj.bdj.2009.1

${ }^{\circledR}$ British Dental Journal 2009; 206: 65-66
The ADEE was established in 1975 at a meeting in Strasbourg. The first drive for ADEE was in the translation of the European Dental Directives to provide guidance for their implementation in dental education. At the 1975 ADEE it was agreed that ADEE should "promote the advancement of dental education in Europe; to foster cooperation and communication among dental and medical educators in Europe and to maintain contact with dental and medical educators in countries elsewhere; to review and evaluate suitable procedures for training dental teachers in Europe'. At this stage ADEE was a relatively small organisation and had fairly slow growth in size until the first EU funded thematic network. In the mid-1990s ADEE initiated the Dent Ed project led by Professor Derry Shanley, of Dublin Dental School. The Dent Ed project was a catalyst to harmonise and equalise dental education standards across Europe. The model was for visitations by small groups of dental educator peers, to help and assist schools. Not only to comply with the European Directives but also to help schools improve their educational experience for the students. The first visit was undertaken in 1996 to Minsk. Since then, the Dent Ed projects have evolved over the past ten years into the final iteration as 'Dent Ed 3'. During this time the original project developed a much broader remit primarily based around school visitations. Over 50 visits have taken place and have resulted in significant development of dental education across Europe. In the past cou- ple of years the visits have expanded further afield, to the Middle East, Turkey and to Russia. These visitations have resulted in a global development in the harmonisation of dental education. With new developments in ADEE and IFDEA (International Federation for Dental Education Associations) the 'Dent Ed' visit has become a model that is becoming adopted worldwide. In the United Kingdom with our background of General Dental Council, there has been a reluctance to invite Dent Ed/ADEE visits. To date there have only been two visits of the ADEE format and both schools report positive outcomes.

Dentistry having a single EU thematic network has allowed a significant advantage over medicine and veterinary sciences which have a number of EU thematic networks, all vying with each other to achieve similar aims. The last of the Dent Ed projects - 'Dent Ed 3', was led by ADEE which now has increased its membership to 185 of the approximately 220 European dental schools. This representational membership has given ADEE the strength to provide strong leadership for dental education in the Europe and a significant worldwide influence.

As part of the Dent Ed projects a number of Task Force groups (Table 1) were established to prepare a number of agreed documents as the basis for achieving the aims of Bologna. It can be seen that the task force outcomes on the profile of the new graduate and curriculum content and structure are those with the greatest impact on UK dental education (Task Forces 1 and 2). 


\section{Profile and competencies for the European dentist}

The Task Force 1 was responsible for the development of the profile competency description of an EU dentist. As part of the process they engaged with government departments, authorities and specialist societies to agree the level and standards that can be expected of a dentist qualifying within the EU. Much of the work and final document was based on the UK General Dental Council's The first five years documents and to many in the UK is very familiar in its terminology and definitions.

This document describes in terms of competencies that the new graduate should have: professionalism, communication, interpersonal skills, knowledge based information handling, critical thinking, clinical information gathering, diagnosis and treatment planning.

This document is now five years old and is due for review in 2008-2009. The challenge for the United Kingdom, having led via the General Dental Council's First five years, is to remain pre-eminent in European dental education. With the GDC currently redefining its role in undergraduate dental education and appearing to be withdrawing from setting standards to a quality assurance role, indicates that Europe will take the lead. In order to ensure that the UK voice is not lost, dental schools and dental educators from the United Kingdom need to be engaged not only in the review process and the feedback that occurs during the evolution of the new document. The impact of the revised document is likely to have a significant effect on the United Kingdom as it will become the standard against which the GDC will have to use to measure educational quality.

\section{Curriculum content and structure}

The second Task Force concentrated on the curriculum content structure and the European Credit Transfer System. Much discussion was around the Bologna model of a three year Bachelor degree followed by a further two years of study for a Masters degree and finally three years study for a Doctorate (PhD). The UK QAA (Quality Assurance Agency) has 'set' the

\section{Table 1 Task Force groups established as part of the Dent Ed project}

\begin{tabular}{|l|l|}
\hline Task Force & Action \\
\hline 1 & Profile of competency of the EU dental graduate \\
\hline 2 & Curriculum content structure and European Credit Transfer System \\
\hline 3 & Quality Assurance and Benchmarking for EU dental education \\
\hline 4 & Organisation of a Global Congress on Dental Education \\
\hline 5 & Establishment of a permanent office for ADEE \\
\hline
\end{tabular}

level of the dental degree at Masters level, but being awarded as a Bachelor degree. It is accepted widely in Europe that the five year dental course (enshrined in EU law) is at Masters level.

The European Credit Transfer System (ECTS) is based upon teaching being in modules and credits awarded for each module completed. This then (in theory) would allow ease of student movement between academic institutions, in that they can gain credits for some modules in a number of universities to the level required for the award of the degree.

The concept of modules is very alien to dental courses as many have worked hard to develop an integrated curriculum where themes and courses inter-relate. The second challenge is that no two dental courses have the same sequencing of timetable which would allow students to gain credit in one subject, then move to another university to gain credit in another.

Two possible degree models were initially proposed: a single cycle five year Masters level degree or a three year/ two year Bachelor/Master cycle with the masters level degree being the level required to register as a dentist in the EU. The advantage of the three-two model is that students who drop out can level the course with recognition for the time spent studying, the Bachelor level degree not being sufficient for registration to practice. The disadvantage is that it could be seen as a fixed break between periods of study to the detriment of integration of the course. It may be that although the Bachelor level exam is taken at three years, no degree is awarded as the student defers the award until completion of the second cycle of two years of study to complete the degree at Masters level. This model is already used in engineering degrees.

The challenge of the Bachelor - Masters degree on graduation in the United Kingdom is progressing, in fact dentistry is well ahead of medicine who appear to be burying their head in the sand and ignoring the issue. The challenge is that of staying with the existing single cycle Masters degree or developing a two cycle Bachelor-Masters course. In theory the challenges of moving to Masters as an exit degree for dentistry is not too high. However, there are challenges in student funding, with the Masters degree being seen as a second degree by HEFCE if the first degree is awarded. Also, many universities require a dissertation for the award of a Masters degree. These changes will have effect on the undergraduate curriculum and if there is the need to introduce research or scholarship to write a dissertation during the undergraduate programme, this will result in a further pressure on the time required to acquire higher and advanced skills and hence squeezing more and more into the already tight and congested curriculum. There has been no steer given by the GDC as where they believe universities should be developing undergraduate degree courses.

Currently the GDC is not providing a lead in UK dental education, as it moves away from its role of visitations and setting of educational standards towards a paper based quality assurance process. This will leave the GDC remote and separate from undergraduate dental education. In these circumstances it is Europe via ADEE that will become responsible for educational standards for the whole of Europe. 